\title{
The Culture-Succession Model: The Factors Affecting Implementation of Succession Planning in Malaysian Public Universities
}

\author{
Abd Rahman Ahmad, Nazia keerio
}

\begin{abstract}
This study aims at exploring the relationship between organizational cultures and succession planning. Succession planning in rapidly changing environment is a significant factor that affects long-term success of the higher education institutions. Previous studies were interested in determining factors that support the implementation of succession planning. Currently, emphasis is more on the role of organizational culture as a factor that can improve succession planning or impede it. However, in Malaysian context, empirical work is limited in relation to these variables. This is quantitative study, the survey questionnaire was used to collect data from academics of Malaysia's public universities. Competing Values Framework (CVF) were used to assess organizational culture; for succession planning items are taken from previous literature. The researchers utilized PLS-SEM after data collection to investigate the role of organizational culture in succession planning implementation. The study finding showed that culture can encourage or be a barrier to succession planning, depends on the values promoted by culture. Particularly, if the institution has a history of clan or hierarchy, the chances of implementation of succession planning tend to be higher. Moreover, when a topdown approach is used in organizations with dominant hierarchy culture and succession planning has a strategic role and formal responsibilities are defined in Clan cultures, succession planning can be enhanced.
\end{abstract}

Keywords: Succession planning, Organisational culture, Higher education institutions, competing values framework (CVF).

\section{INTRODUCTION}

Universities are frequently operating into a dynamic environment where they must adapt in order to compete and survive [1], but success in such an environment needs leaders who are extremely capable and effective [2]. Within this context, succession planning is considered critical for developing future leaders to achieving viable competitive advantages for universities success [3]. In addition, the old assumptions regarding leadership can no longer be admired in today's fast-moving, high-tech, and diverse society [4]. As Calareso [5] states, the traditional way to the preparation of the future leaders in universities, which includes gaining a doctorate and then becoming tenure-track faculty, full professor, chair, dean and deputy vice chancellor, is no longer an adequate path to prepare future leaders for higher education institutions.

Revised Manuscript Received on October 30, 2019.

* Correspondence Author

Abd Rahman Ahmad*, Associate Professor, Faculty of Business and Technology Management, Universiti Tun Hussien Onn Malaysia.

Nazia Keerio, Faculty of Business and Technology Management, Universiti Tun Hussien Onn Malaysia.

(C) The Authors. Published by Blue Eyes Intelligence Engineering and Sciences Publication (BEIESP). This is an open access article under the CC BY-NC-ND license (http://creativecommons.org/licenses/by-nc-nd/4.0/)
Burke [6] describes succession planning as a mechanism to match individual's ability with growing needs of organizations and equip workers with tools and skills needed to develop into new leadership roles. A systematic approach to succession planning is therefore needed in order to broaden the leadership pipeline rapidly and future preparation of universities [1]. Previous research shows the positive relationship between succession planning and sustainability of organization. Despite of the importance of succession planning for organizational stability, few institutions have succession plans in place [7]. Nevertheless, researches have shown that many institutions of higher education do not successfully execute succession planning strategies to support their workers $[1,8]$.

Given the importance of succession planning in institutional continuity, numerous studies have attempted to enhance the practices of succession planning by investigating the various factors [9, 10]. Organisational culture is currently considered to have more impact on the preparation of successions than other factors $[3,4,11,12]$. In this view, succession planning can also be carried out through a strong organisational culture of values, standards, beliefs, and paradigms for all workers that institutions have. Employees in their regular work will exercise these values, standards, beliefs, and paradigms. Therefore, if these values and standards support the system of succession planning, workers would also follow the program [9].

While empirical research in this area is minimal, the literature showed that culture is stimulating to enhance or barrier to succession planning. Some of the studies also analyse the cultural characteristics of the relationship between succession planning and organisational culture [13] whereas other studies used the different cultural characteristics or typologies [3, 4, 11, 12]. In the meantime, some current studies recommend empirical research to further investigate the relationship between organisational culture and succession planning $[9,13]$.

The purpose of the study is to eliminate the differences in succession planning and organisational culture in the literature. A literature review on the best practices related to succession planning was performed in the first section and contrasted with the cultural dimensions defined in the Competing Values Framework. The research's objective is to define which model or type of culture facilitates further implementation of succession. The debate on empirical studies on the relationship between organisational culture and succession planning was discussed in the second section. The last paragraph draws the study's conclusion and proposes further research into the subject for future consideration. 


\section{LITERATURE}

In this section, we review previous research on succession planning and organisational culture with a focus on work by Cameron and Quinn [14]. We also summarize the findings on the relation between succession planning and organisational culture.

\section{A. Organisational culture}

In the late 1960s, the theory of culture began to take the lead in management science [15]. The idea of a society formed by individuals coming together in accordance with certain values can, as a whole, be viewed mainly as the individual's protection against the physical environment. One of the most complete definitions was related to Taşkıran, et al. [16] the beliefs, values, and opinions of individuals who form society are to recognize organisational culture as quite monotonous. This description was useful because it took part in the common essence of culture and behaviour [17]. Some say organisational culture can be characterized as the set of beliefs, principles, behaviours, by certain human communities that influence the institution's way of working, as well as other institutional activities. Organisational culture, on the other hand, relates to how the company conducts its operations. Organisational culture is, therefore, one of the institution's significant distinguishing factors [16]. Numerous studies in a wide range of contexts have recognized the importance of organisational culture in assessing an institution's success or failure [18].

Organisational culture typically involves defining shared values, principles and expectations within an institution that an individual has. Several researchers and experts have discussed corporate culture principles. Values are expectations for desirable outcomes and ways to achieve certain outcomes. Organisational culture has identified organisational leaders ' shared experiences to influence their behaviour [19]. The physical characteristics of cultural values such as open communication, collaboration, innovation, and justice are reflected [16]. Assumptions are widely held, unconscious views of human nature are built in, and social interactions are disregarded. Artefacts include more strong and tangible social depictions, including ceremonies, slogans, beliefs and myths [17].

Cameron and Quinn [14], explained that the culture of an institution resonates with what is valued, dominant management and leadership styles, language and signs, processes and habits, and how an institution defines success that is special to that institution. While, Schein [20] claims that social perceptions affect not only individuals and style, but also methods, processes, and systems. What is required first is to understand the organisational culture in order to research organisational analysis. Furthermore, scholars such as Smircich [21] and Cameron and Quinn [14] argued that corporate culture was studied from two different perspectives: an anthropological and sociological viewpoint. The first group considers organisational culture to be something institutions are, whereas the latter group considers organisational culture to be something institutions have. Particularly, the essential difference between these two origins, as Smircich [21] and Cameron and Quinn [14] argue, is that one defines culture as a metaphor (anthropology) argued that one describes culture as a showed that culture existed at both the level of belief and and outcomes of other interpersonal relationships generated

metaphor (anthropology) and the other as an attribute or factor (sociology). Distinctive approaches have been developed within each of these two roots: a common behavior-based functionalist approach and a semiotic approach based on individual perceptions and cognitions. Cameron [22] stated that the anthropological viewpoint considers culture to be a dependent variable, while the sociological perspective considers culture to be an independent variable. The Functionalist approach was adopted by scholars like Peters, et al. [23] and Deal and Kennedy [24], to assess which culture will achieve the best results. In comparison, the Semiotic approach has become popular among most academics [21]. Their research investigated how workers view an institution's environment and how this influences their actions towards the institution. The culture was important because organisational culture could have a significant impact on institutions in areas such as quality and aspects relevant to employees [17]. In addition, several authors have studied extensively the significance of organisational culture in institutions [14, 20, $25]$. The management of these cultures was a difficult and vague job for business leaders, despite the fact that companies have always had cultures [25]. Cameron and Quinn [14] Arguing that corporate culture is strongly linked to the institution's sense of identity, beliefs, purpose, objectives, goals, and ways of creating common values. Likewise, an institution's culture characterizes the abstract and unquestionable system of beliefs that defines how an institution operates. Such convictions, however, are mostly misunderstood and are not always openly discussed [20]. Therefore, culture could be a powerful resource with a common purpose of identification and versatile guidelines. Its effect on members was so strong that members ' behaviour, emotions, beliefs and attitudes could be identified by analysing their measurements, and their probable reaction to desired changes was investigated, predicted and guided [19]. In addition, organisational culture is considered to be one of the unique features that differentiate effective organisations from others [17]. It is, therefore, a vital challenge for leaders to understand the concept of organisational culture because of its great impact on various aspects of organisational behaviour. Ignoring organisational culture in the preparations for any institutional reforms would have unintended and negative consequences [14].

From the previous discussion of measuring organisational culture, it is apparent that the research and analysis of organisational culture have many approaches. All these models are studying organisational culture from viewpoints that are informed by social culture studies. In order to study organisational culture accurately, a consistent model was pursued in institutions that are not the scope of this study, which can calculate organisational rather than societal cultural dimensions. The CVF developed by Cameron and Quinn [14] provides a more focused study of organisational culture.

\section{B. Competing Values Framework}

The theory of organisational effectiveness developed by Cameron Kim and Quinn Robert [26], known as the competing values framework (CVF). 
The authors found that, based on an analysis of sensibly selected items, a two-dimensional model seemed to profoundly classify characteristics of high salience to organisational culture. They specifically identified that organisational culture can be typologically understood by plotting attitudes against its emphasis (internal versus external) of the structure of an institution (flexible versus controlled). The resulting two-dimensional conspiracy created four forms of organisational culture: (a) family, (b) adhocracy, (c) business, or (d) hierarchy. It is, therefore, necessary to understand these contrasting principles of structure and emphasis as alternative examples of potentially effective organisational cultures [27].

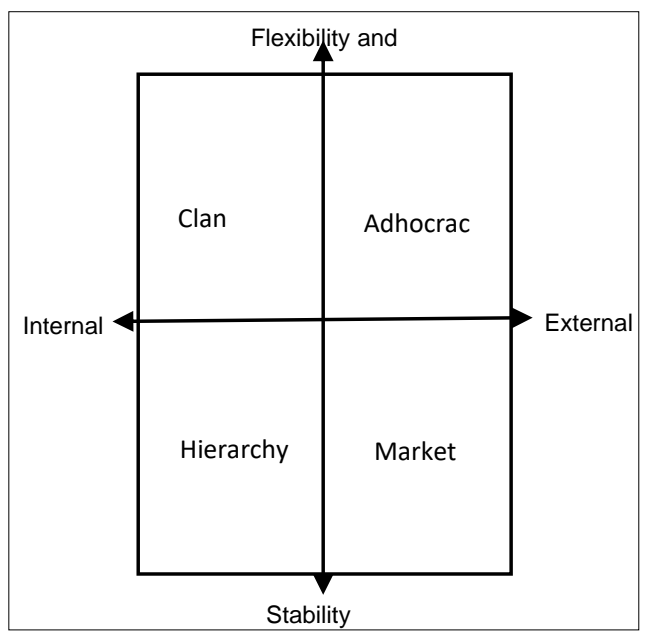

Fig 1 Cameron and Quinn model (1999)

\section{Clan culture}

Clan represents a community that is similar to a familytype organisation, is less dependent on structure and power, and is more concerned with flexibility. The value-enhancing practices that contribute to organisational performance in the Collaborate Quadrant deal with developing human skills, human development motivation, human involvement and high levels of interaction with participants [28]. Examples of activities in this area include clarifying and improving corporate principles, standards, and expectations; cultivating staff and cross-functional working groups; implementing employee retention programs; and promoting team building and collaborative decision-making [29]. The core of clan culture is a shared value institution and this shared value can influence many of an individual's attitudes [26].

Table I Indices of Clan culture

\begin{tabular}{l|l}
\hline Dominant characteristics & Personal, like a family \\
\hline Leadership style & Mentoring, facilitating, nurturing \\
\hline Management of employee & Teamwork, consensus, and participation \\
\hline Organisational glue & Loyalty and mutual trust \\
\hline Strategic emphasis & $\begin{array}{l}\text { Human development, high trust, } \\
\text { openness }\end{array}$ \\
\hline Criteria for success & $\begin{array}{l}\text { Development of human resource, } \\
\text { teamwork, concern for people }\end{array}$ \\
\hline
\end{tabular}

\section{Hierarchy culture}

Hierarchy culture is enabled by an organisational structure driven by control mechanisms, and the corporate goal is to create value through internal efficiency improvements, the introduction of improved processes (e.g., systematic use of procedures, systems, and technology) and quality improvements (e.g. numerical process management and other quality control processes). Institutions with this culture typically use structured procedures widely and emphasize reinforcement and uniformity of rules. For high-control institutions, by replacing the leader of a very hierarchical system, the board would be hesitant to address problems. Control has always been a major factor in organisational research and a major contributor to the culture of organisation [14].

Table II Indices of Hierarchy culture

\begin{tabular}{l|l}
\hline Dominant characteristics & Controlled and structured. \\
\hline Leadership style & $\begin{array}{l}\text { Coordinating, organizing, efficiency } \\
\text { oriented }\end{array}$ \\
\hline Management of employee & Security, conformity, predictability \\
\hline Organisational glue & Formal rules and policies \\
\hline Strategic emphasis & Performance and stability \\
\hline Criteria for success & Dependable, efficient, low cost \\
\hline
\end{tabular}

\section{E. Market culture}

Compete (Market) culture defines externally focused organisations with more emphasis on structure and control and less regard for flexibility and risk. Referring to Cameron \& Quinn this type of organisation was well known as it was not only the solution to new competitive challenges but also the network-related transactional activity such as clients, vendors, contractors, unions, etc. [14]. In fact, a Compete Culture organisation's main goals are to generate profits, achieve bottom-line results, improve competitive niches, broaden expectations, and retain old customers. This quadrant emphasizes internal and controls value creation and efficiency[26].

\section{Table III Indices of Market culture}

\begin{tabular}{l|l}
\hline Dominant characteristics & Competitive, achievement oriented \\
\hline Leadership style & No-nonsense, aggressive, result oriented \\
\hline Management of employee & Competitiveness and achievement \\
\hline Organisational glue & $\begin{array}{l}\text { Emphasis on achievement and goal } \\
\text { accomplishment }\end{array}$ \\
\hline Strategic emphasis & Competitive actions and winning \\
\hline Criteria for success & $\begin{array}{l}\text { Winning in the marketplace, outpacing } \\
\text { the competition }\end{array}$ \\
\hline
\end{tabular}

\section{F. Adhocracy culture}

Culture of adhocracy is a culture in which organisations are externally focused and rely less on structure and control but more on agility and risk tolerance. It concerns the transition from the industrial to the information age and aims to be more versatile as the Collaborative Culture and externally oriented as the Compete Culture [14]. Cameron and Quinn referred to this type of culture as an organisational form more sensitive to hyper-turbulent, everaccelerating conditions that increasingly define the twentyfirst-century organisational environment. Cameron explains that adhocracy culture contributes to organisational change through flexible, entrepreneurial, innovative and high-risk workplace orientation [26].

Table IV Indices of Adhocracy culture

\begin{tabular}{l|l}
\hline Dominant characteristics & Entrepreneurial, risk taking \\
\hline Leadership style & Entrepreneurial, innovative, risk taking \\
\hline Management of employee & $\begin{array}{l}\text { Individual risk taking, innovation, } \\
\text { freedom, and uniqueness }\end{array}$ \\
\hline Organisational glue & commitment to innovation, development \\
\hline Strategic emphasis & $\begin{array}{l}\text { Acquisition of resources, creating new } \\
\text { challenges }\end{array}$ \\
\hline Criteria for success & Unique and new products and services \\
\hline
\end{tabular}




\section{G. Succession planning}

Originally, the purpose of succession planning is to ensure an organisation's growth and sustainability. Succession planning is a proactive measure in this regard to recognize high potential and establish suitable leadership successors that support an organisation's creation, growth and sustainability [17]. Likewise, Rothwell [30], defined succession planning as:

'...deliberate and systematic efforts by an organisation to ensure leadership continuity in key positions, retain and develop intellectual and knowledge capital for the future, and encourage individual advancement'.

The importance of succession was repeated by many scholars. In the view of this Darvish and Temelie [31] Discussed the succession planning partnership with organisational strategies. Succession planning is therefore defined as a stabilizing organisational strategy in the light of the issue of increased retirement in higher education institutions [31]. Darvish and Temelie [31] provided arguing that higher education institutions often pursued informal succession planning strategies resulting in ineffective or poor efforts. In the meantime, succession planning will reduce the gaps in vacancies in key operations and program roles. Authors, therefore, suggested a way to accomplish missions and goals within organisations in the form of a systematic approach to succession planning [31].

Kumar and Kota [32] conducted a succession case in higher education institutions. At times of uncertainty, the authors found succession planning as professional development and organisational stability [32]. In addition, the researchers addressed concerns about organisational strategic direction by emphasizing the interaction of proposals with stakeholders to minimize uncertainty [32]. In addition, according to the study of Kamil, et al. [33] succession planning facilitates the continuity of organisations and the success of the programs of the institutions.

Succession plans can be an effective strategy to fulfil the institution's mission as employees leave [30]. According to Calareso [5], Lack of effective succession planning may lead to institutional deprivation of the future. Burke [6] suggested a depriving future is due to the sub-optimal decisions and operations carried out most of the time during vacancies in key positions. According to Stephens [34], when vacancies occur, in the absence of succession planning institutions may enter the rapid crisis mode. Therefore, institutions can be helped to handle crises by integrating succession planning with strategic planning and also by adopting correct policies and decisions amid the turnover of employees [5, 6].

\section{H. The relationship between organisational culture and succession planning}

Given the importance of succession planning in higher education performance, many studies have tried to identify its key determinants [9]. These can usually be classified at the level of the organisation and culture at the individual level. The literature applies to leadership-style career development knowledge management leadership development of human resources financial support activities and organisational culture within the organisational level. Of all these, leadership growth and organisational culture are the most significant $[9,35,36]$.
Organisational culture can be defined as what is valued, the prevailing styles of leadership, language and symbols, procedures and routines, and definitions of success that make an organisation unique [14]. Mehrabani and Mohamad [9], having a strong organisational culture with principles, ideals, expectations, and paradigms for all workers often influences successful succession planning. They hoped that workers could see these principles, ideals, expectations, and paradigms as guidance for their everyday success. Therefore, if the succession planning process were driven by these values and standards, workers would also obey the system. Therefore, organisational culture plays a major role in the selection of high potential future leaders in succession planning [3].

Empirical research has also shown an important relationship between culture and succession [3, 4, 9, 11-13, 33, 35-39]. What has not been properly explained in the literature on the subject is what kinds of culture boost or hinder succession planning.

In order to recognize the features of a culture of the organisation, the model proposed by Cameron Kim and Quinn Robert [26] was used, the Competing Values Framework (CVF), This model is significant and commonly used in organisational culture studies.

Cameron Kim and Quinn Robert [26] Describe four forms of culture: adhocracy, family, market and hierarchy; using two dimensions (see Fig. 1): mobility and choice as opposed to stability and control and external emphasis as opposed to an internal focus. We formed four styles of organisational cultures with six organisational aspects: dominant characteristics, leadership of organisations, management of employees, organisational glue, strategic focus, and criteria for success.

The culture of adhocracy is internally oriented; it stresses versatility and transition. Therefore, these organisations work in competitive environments and have embraced the philosophy of adhocracy in finding leaders in their markets. The fundamental values in a culture of adhocracy are innovation, entrepreneurship, and risk-taking. While, versatility is also emphasized by a clan community, but it is centred internally. Teamwork, employee engagement, and organisational responsibility to workers are characteristics of clan culture firms. A consumer culture, on the other hand, is command and stability and is focused externally. Goal accomplishment, reliability, and efficiency are the core values of business culture. Likewise, a culture of hierarchy is also control-oriented, but it focuses on internal organisation. The fundamental values are performance and strong alignment with requirements, rules, and regulations [40].

Having defined the types of models suggested by Cameron and Quinn [14], and the relationship between the types of organisational culture and succession planning has been investigated. First, a literature review that analyses the principles of community which encourage succession planning. Four characteristics or cultural values that promote succession planning are generally agreed: recognize high potential, develop skills, include top management [10, 30]. 
In terms of supporting and involving senior management, succession planning depends on senior management's dedication and support [30]

and Succession planning is accomplished by personal involvement which motivates the participants and ensures that the other management team members commit time and effort to prepare. An institution also needs current leaders to help the processes, not only in the development of future leaders, but also in the recruitment, assessment, and implementation of succession planning [41]. Hence, top management engagement should, therefore, on the one hand, motivate workers to engage in succession planning programs [42], and, on the other hand, encourage them to look for career growth, although the importance of the results may not be obvious [30, 42].

High potential recognition and production is the basis for the internal growth of successors in leadership [30], and is one of the most common elements associated with succession planning. High potential growth is the cornerstone of any strategy for succession planning and management [6, 30]; however, development cannot take place without sufficient recognition of high potential. A high potential is an outstanding current performer capable of advancing several rates beyond the current position; and highly valued for current and future success [30].

It is important to compare individual employees ' current and expected future results, as such comparison helps to expose their latent potential for future use in key positions [30]. In addition, to know how to train future leaders, it is necessary to identify skills and competences for each level of leadership and role [41]. In addition, this activity includes evaluating the current and future work requirements and the competence of an entity's key positions [43].

A comparison of the above-mentioned characteristics with the styles of culture developed by Cameron Kim and Quinn Robert [26] leads to the conclusion that flexibility-oriented cultures improve succession planning because flexibility is correlated with the recognition of high potential, the creation of talents, the participation of top management and the filling of vacant positions. While the culture that stresses stability and control that inhibit planning for succession. In addition, more than externally oriented cultures can be expected to foster succession planning.

Then, the CVF culture type that most promote succession planning is supposed to be a clan culture because it emphasizes flexibility and is internally focused. On the contrary, a patriarchal society delays succession planning because it is hampered by the principles it emphasizes: power and continuity and an inner focus.

It is important to explore their characteristics in order to clarify the relationship in relation to the other two forms of culture model (the market and the adhocracy). It can promote succession planning, taking into account the characteristics of a culture of adhocracy, a sit emphasizes creativity and innovation. If the work team has a number of talented interdisciplinary leaders who come up with creative and innovative ideas to execute the project, then succession planning will be encouraged [40]. Empirical studies on this subject, however, given evidence is non-conclusive. Whereas Darvish and Temelie [31] notice organisations using informal succession planning methods. Finally, SanzValle, et al. [40] observed that a dynamic and internal oriented organisational culture is inversely related to succession.
In short, there is no clear relationship between succession planning and an adhocracy or business culture. Only strong reasons and evidence for the relations between a clan culture or a hierarchy culture and succession planning are presented by the literature on the subject. Therefore, the following hypothesis is proposed:

- H1: There is a relationship between organisational culture and succession planning at Malaysian public universities.

- H1.1: There is a relationship between clan culture and succession planning at Malaysian public universities.

- H1.2: There is a relationship between adhocracy culture and succession planning at Malaysian public universities.

- H1.3: There is a relationship between hierarchy culture and succession planning at Malaysian public universities.

- H1.4: There is a relationship between market culture and succession planning at Malaysian public universities.

\section{METHODOLOGY}

This section presents our study's research method. In this section present the research design, the measurement instrument and the data collection process of the study.

\section{A. Research design}

This research followed a quantitative research design to collect and analyse data. The purpose of quantitative research is to develop phenomena-related theories, hypotheses, and models. The aim of this study is to investigate the relationship between organizational culture and succession planning. This requires the quantitative processing of data, which is then analysed quantitatively.

\section{B. Data collection and analysis}

A survey was conducted in Malaysia's public sector research universities. An online survey was conducted as well as the questionnaire's printed copies also distributed to academic staves in public universities in Malaysia. Completely anonymity was promised to all respondents. The survey was designed to cover a wide range of succession planning (19 questions) and organisational culture (20 questions). The questionnaire consisted of three sections; respondents demographics, organisational culture, and succession planning. The items for succession planning was adopted from previous literature $[10,30]$. Based on the OCAI assessment, organisational culture is evaluated based on the answers to 20 questions [14]. The research used the scale of seven-point likert. We checked for sample data normality. Results show that usually data is not normally distributed. Therefore, for the study, non-parametric tests were used. Further to investigate the role of organisational culture in implementing succession planning, structural equation modelling has been conducted. The survey results were analysed using version 3.2.7 of the smart PLS-SEM software. 


\section{RESULTS}

Using the PLS-SEM methodology with Smart PLS v.3.2 code, the proposed model has been evaluated [44]. Structural equation modeling (SEM) is a commonly used technique in recent academic literature and is considered suitable for the early stages of the theory creation where the research interests lie in testing different and complex relationships between latent variables at the same time using a small sample size SEM usually suggests a two-step method to conduct PLS statistical analysis properly [45]. Next, the methods of measurement (outer models) are validated. The structural model (inner model) is checked in a second step by applying the resampling procedures (i.e., bootstrapping) to 5,000 resamples [46].

Following this suggestion, in order to examine internal consistency, the external model was evaluated first. There are three steps in this phase [47]. The first stage includes testing the reliability of the individual indicators using their external loadings to determine the extent to which each indicator of the construct is substantially associated with their respective latent variable. The thumb rule on quality of internal products is to consider objects with loads of 0.70 or higher. The indicators were dropped from the original model with lower outer loads. All outer loadings were at least 0.70 in the five reflective measuring versions.

Composite reliability (CR) is tested in the second stage by evaluating Cronbach's alphas showing whether the parameter array is compatible with what it aims to test. All multidimensional structures and dimensions satisfy the consistency of the appropriate construct as their CRs are higher than the normal 0.70. In general, for succession planning, the CR scores range from 0.81 for the Hierarchy culture to 0.94. Therefore, concluded that the measuring items, as indexed by the CR, were reliable in terms of their internal consistency and reliability. Convergent validity was assessed using the average extracted variance (AVE) for all latent constructs, including reflective indicators and variable loading criteria [48]. Factor loading with any construct should be greater than 0.70and AVE than the square of its largest correlation. Such specifications were fulfilled by all reflective measurement model. Some items ' factor loading ranges from 0.70 to 0.88 , which supports convergent validity. The third stage, a discriminating validity study, decides whether each model construct varies substantially from the other. By comparing the AVE values with the square variables correlation [49], it is also confirmed the existence of discriminating construct validity since the AVE values are higher than the predicted square correlations. Following Henseler, et al. [50] suggested that the heterotrait-monotrait (HTMT) ratios are all below 0.85 and the upper confidence limits are below 1 . These results of HTMT show satisfactory discriminating validity within the information. These findings together provide enough assurance that the model of reflective measurement fits well with the data.

Table V Results of measurement model

\begin{tabular}{|c|c|c|c|c|}
\hline $\begin{array}{c}\text { Constr } \\
\text { uct }\end{array}$ & Items & $\begin{array}{c}\text { loading } \\
\text { s }\end{array}$ & AVE & $\begin{array}{c}\text { CR/ } \\
\text { VIF }\end{array}$ \\
\hline Clan & Clan1 & 0.834 & 0.650 & 0.902 \\
\hline & Clan2 & 0.874 & & \\
\hline
\end{tabular}

\begin{tabular}{|c|c|c|c|c|}
\hline & Clan3 & 0.865 & & \\
\hline & Clan4 & 0.685 & & \\
\hline & Clan5 & 0.756 & & \\
\hline \multirow[t]{5}{*}{ Adhoc } & $\begin{array}{c}\text { Adhoc } \\
1\end{array}$ & 0.765 & 0.741 & 0.935 \\
\hline & $\begin{array}{c}\text { Adhoc } \\
2\end{array}$ & 0.872 & & \\
\hline & $\begin{array}{c}\text { Adhoc } \\
3\end{array}$ & 0.881 & & \\
\hline & $\begin{array}{c}\text { Adhoc } \\
4\end{array}$ & 0.902 & & \\
\hline & $\begin{array}{c}\text { Adhoc } \\
5\end{array}$ & 0.879 & & \\
\hline \multirow[t]{5}{*}{ Hier } & Hier1 & 0.791 & 0.610 & 0.879 \\
\hline & Hier2 & 0.337 & & \\
\hline & Hier3 & 0.914 & & \\
\hline & Hier4 & 0.862 & & \\
\hline & Hier5 & 0.855 & & \\
\hline \multirow[t]{5}{*}{ Mark } & Mark1 & 0.824 & 0.636 & 0.896 \\
\hline & Mark2 & 0.608 & & \\
\hline & Mark3 & 0.850 & & \\
\hline & Mark4 & 0.856 & & \\
\hline & Mark5 & 0.822 & & \\
\hline \multirow[t]{16}{*}{ SP } & SP1 & 0.744 & 0.556 & 0.959 \\
\hline & SP10 & 0.750 & & \\
\hline & SP11 & 0.824 & & \\
\hline & SP12 & 0.550 & & \\
\hline & SP13 & 0.589 & & \\
\hline & SP14 & 0.637 & & \\
\hline & SP15 & 0.834 & & \\
\hline & SP16 & 0.618 & & \\
\hline & SP17 & 0.759 & & \\
\hline & SP18 & 0.817 & & \\
\hline & SP19 & 0.831 & & \\
\hline & SP2 & 0.788 & & \\
\hline & SP3 & 0.770 & & \\
\hline & SP4 & 0.597 & & \\
\hline & SP5 & 0.773 & & \\
\hline & SP6 & 0.773 & & \\
\hline
\end{tabular}




\begin{tabular}{|l|c|c|l|l|}
\hline & SP7 & 0.702 & & \\
\hline & SP8 & 0.836 & & \\
\hline & SP9 & 0.860 & & \\
\hline
\end{tabular}

The hypotheses presented in the model were checked, having satisfactory values of the convergent and discriminating validity of the measurement model. We studied the impact on succession planning of each aspect of the organisational culture, testing the importance of the path coefficients and their significance (we applied the bootstrapping procedure on 5000 subsamples).

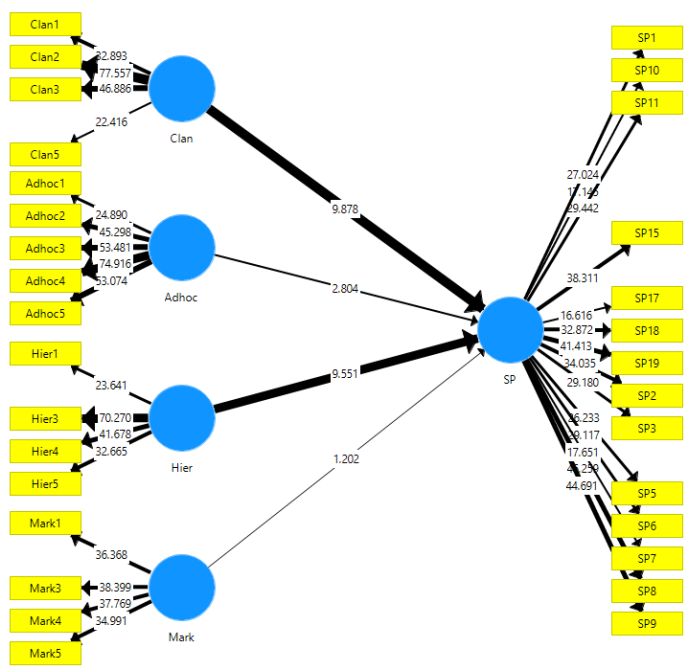

Fig 2 Research framework

Hypothesis 1 indicates that succession planning is influenced by organisational culture and that the sign may vary depending on the culture type. Further, to test this hypothesis, the prototype was separately introduced into the four models of organisational culture. Table 2 shows the results obtained. The clan culture has a positive impact on succession planning as predicted, and the hierarchy culture has a positive impact on succession planning as well. Although there is no connection between the culture of adhocracy and succession planning while the relationship between market culture and succession planning has no effect.

Table VI Results of structural model

\begin{tabular}{|l|l|l|l|l|l|l|}
\hline $\begin{array}{l}\text { Relation } \\
\text { ships }\end{array}$ & $\begin{array}{l}\text { Std. } \\
\text { beta }\end{array}$ & $\begin{array}{l}\text { Std. } \\
\text { Error }\end{array}$ & $\begin{array}{l}\text { t- } \\
\text { value }\end{array}$ & $\mathbf{R}^{2}$ & $\mathbf{f}^{2}$ & $\begin{array}{l}\mathbf{p} \\
\text { value }\end{array}$ \\
\cline { 1 - 4 } $\begin{array}{l}\text { Adhoc - } \\
\text { >SP }\end{array}$ & 0.103 & 0.037 & 2.804 & & 0.027 & 0.005 \\
\cline { 1 - 3 } $\begin{array}{l}\text { Clan - } \\
\text { >SP }\end{array}$ & 0.427 & 0.043 & 9.878 & & 0.738 & 0.000 \\
\cline { 1 - 3 } \cline { 6 - 7 } $\begin{array}{l}\text { Hier - } \\
\text { >SP }\end{array}$ & 0.432 & 0.045 & 9.551 & & 0.302 & 0.000 \\
\cline { 1 - 3 } $\begin{array}{l}\text { Mark - } \\
\text { >SP }\end{array}$ & 0.030 & 0.025 & 1.202 & & 0.003 & 0.230 \\
\hline
\end{tabular}

\section{DISCUSSION}

The findings provide proof of the relationship between culture and succession. The findings showed that organisational culture is a primary determinant of succession planning as well as being able to foster and act as a barrier to succession planning. In general, findings showed the clan culture's positive influence on succession planning. Other traits such as human development, teamwork, and nurturing associated with the culture of clan promote implementation of succession planning, as described in the literature on the subject. The hierarchy culture's negative impact on succession is also consistent with research that has shown that the features of hierarchy culture, such as hierarchical decision-making and a high degree of formalization, are negatively associated with succession. No important result was found with respect to the ideology of adhocracy and market. While some studies point out that the influences of clan culture, such as imagination, contribute to succession planning, they may only influence succession if there are other values correlated with external orientation. Anything similar happens with respect to the effects of the market culture. Although the customer orientation that characterizes the market culture and also the clan culture has a positive effect on succession planning, other features, such as stress on the mechanistic structure, excessive hierarchy, emphasis on information, and exerting excessive pressure on succession, may reduce the positive effect of its external focus on succession planning. Along those lines, SanzValle, et al. [40] Indicate that business focus is not always adequate and must be followed by other factors, such as the training of workers, which are lacking in the culture of the public sector. Considering the results for the four styles of culture, it can be concluded that flexibility versus stability and control orientation is more important when it comes to success than external orientation versus internal orientation. Or put it another way, or enhance succession planning, flexibility is a must. External orientation is better than external orientation, but in order to have a positive effect on succession planning, it must be paired with versatility. This suggestion is in line with the suggestions made by some previous researchers that certain characteristics of nonadaptive societies are associated with low performance [21].

\section{CONCLUSION}

We investigated in this paper the role of organisational culture in implementing succession planning in Malaysia's public universities. With 291 academics, we conducted a survey and collected data on succession planning and organisational culture from Malaysian public universities. Our study provides empirical perspectives in different corporate cultures on the application of succession planning. Indeed, there seems to be a greater chance of success:

- If succession planning is carried out throughout the institution if the institution has a history of clan or hierarchy;

- When using a top-down strategy in institutions with a dominant hierarchical structure;

- When there is a strategic role in succession planning and formal roles are established in clan cultures.

The consequences of the above findings are evident to practitioners. An institution looking to develop succession planning must pay attention to its organisational culture as it can be a key enabler or a significant obstacle based on 

culture. In general, the results of this research showed that succession planning is promoted by the clan culture.

Some of this culture's core principles are team work, human resource growth, people care, and transparency. Institutions must, therefore, make efforts to create a cohesive culture of the clan. It is also important to emphasize that this study showed to improve succession planning, an internal orientation or a flexibility orientation is not enough for the organisation. Nonetheless, as performance enhancement requires flexibility, top management must concentrate on improving performance. In short, the results of this research may direct leader's efforts to develop a culture of organisation that promotes succession planning.

\section{LIMITATIONS}

Our results must be appreciated taking into account certain possible limitations. Next, a complex structure is organisational culture. Our research focuses only on one country's organisations. Differences in national culture could be discussed (Hofstede, 1993) may restrict the widespread use of our findings to other countries. Future studies should, therefore, reproduce the development of research in countries with different national culture profiles. The downside of using quantitative research is that respondents have restricted responses choices and are focused on expectations. Our research focuses on the role of organisational culture affecting succession planning implementation. Examined theories and structures are predetermined. In order to provide an in-depth understanding of the problem, future research using a mixed methods approach is needed.

\section{ACKNOWLEDGEMENTS}

The authors would like to thank Universiti Tun Hussein Onn Malaysia for supporting this research under the Research funds UTHM (E15501) and GPPS U730. In addition, the authors also thank the respondents for their fully supported in this research.

\section{REFERENCES}

1. J. Clunies, "Benchmarking succession planning \& executive development in higher education," Academic Leadership: The Online Journal, vol. 2, no. 4, p. 3, 2004.

2. D. C. Bisbee and M. T. Miller, "A Survey of the Literature Related to Executive Succession in Land Grant Universities," Online Submission, 2006.

3. R. C. Richards, Succession planning in higher education: The influenceof culture on the succession process ina community college. Mercer University, 2016.

4. C. L. Richards, A new paradigm: Strategies for succession planning in higher education. Citeseer, 2009.

5. J. Calareso, "Succession planning: the key to ensuring leadership: the key is that the process of leadership formation is not random and serendipitous, but rather intentional and well planned," Planning for Higher Education, vol. 41, no. 3, pp. 27-34, 2013.

6. W. W. Burke, Organization change: Theory and practice. Sage Publications, 2017.

7. K. V. Nakutis, "Collegiate leadership: A case study of succession planning and selection strategies for effective university presidential selection," Northcentral University, 2016.

8. J. D. Baker, "Succession planning: A perioperative imperative," AORN journal, vol. 6, no. 105, pp. 538-540, 2017.

9. S. E. Mehrabani and N. A. Mohamad, "Identifying the important factors influencing the implementation of succession planning," in values including the organisation's existing organisational

International Conference of Information and Finance, 2011, vol. 21, no. 1 , pp. 37-41.

10. P. E. Mateso, "Understanding succession planning and management efforts at Midwestern University: A mixed methods study," Bowling Green State University, 2010.

11. L. Fancher, "The Link between Culture and Succession Planning," in The Cultural Context of Human Resource Development: Springer, 2009, pp. 233-247.

12. J. P. Tan, "An investigation of corporate leadership succession planning and implementation: the Malaysian experience: a thesis submitted to the University in fulfilment of the requirements for the degree of Doctor of Philosophy in Management, Massey University," Massey University, 2009.

13. N. Shabankareh, N. Madani, and W. Shiralizadeh, "The Relationship between Organizational Culture and Employee Succession Planning in Keshavarzi Bank Branches in Tehran," International Journal of Academic Research in Business and Social Sciences, vol. 5, no. 4, pp. 198-210, 2015.

14. K. S. Cameron and R. E. Quinn, Diagnosing and changing organizational culture: Based on the competing values framework. John Wiley \& Sons, 2011.

15. M. T. L. Fleury, "Organizational culture and the renewal of competences," BAR-Brazilian Administration Review, vol. 6, no. 1, pp. 1-14, 2009.

16. E. Taşkıran, C. Cetin, A. Özdemirci, B. Aksu, and M. Istoriti, "The Effect of the Harmony between Organizational Culture and Values on Job Satisfaction," International Business Research, vol. 10, no. 5, 2017.

17. M. Farzin and M. G. Azizi, "An Investigation on the Relationship between Organizational Culture and Knowledge Management Strategy (Case study: Islamic Azad University; Area Three)," Asian Journal of Research in Business Economics and Management, vol. 4, no. 7, pp. 307-313, 2014.

18. M. M. Naqshbandi, S. Kaur, R. Sehgal, and I. D. Subramaniam, "Organizational culture profile of Malaysian high-tech industries," Asia-Pacific Journal of Business Administration, vol. 7, no. 1, pp. 2 19, 2015.

19. C. Adams, A. Dawson, and M. Foureur, "Competing Values Framework: A useful tool to define the predominant culture in a maternity setting in Australia," Women and Birth, vol. 30, no. 2, pp. 107-113, 2017.

20. E. H. Schein, Organizational culture and leadership. John Wiley \& Sons, 2010.

21. L. Smircich, "Concepts of culture and organizational analysis," Administrative science quarterly, pp. 339-358, 1983.

22. K. S. Cameron, "The conceptual foundation of organizational culture," 1988.

23. T. J. Peters, R. H. Waterman, and I. Jones, "In search of excellence: Lessons from America's best-run companies," 1982.

24. T. E. Deal and A. A. Kennedy, "Culture: A new look through old lenses," The journal of applied behavioral science, vol. 19, no. 4, pp. 498-505, 1983.

25. D. R. Denison and G. M. Spreitzer, "Organizational culture and organizational development: A competing values approach," Research in organizational change and development, vol. 5, no. 1, pp. 1-21, 1991.

26. S. Cameron Kim and E. Quinn Robert, "Diagnosing and Changing Organizational Culture," Bk: Addison-Wesley Publishing Company, 1999.

27. J. A. Kaufman, "Organizational culture as a function of institutional type in higher education," 2013.

28. K. S. Cameron, "Cultural Congruence, Strength, and Type: Relationships to Effectiveness. ASHE 1985 Annual Meeting Paper," 1985.

29. L. W. Howard, "Validating the competing values model as a representation of organizational cultures," The international journal of organizational analysis, vol. 6, no. 3, pp. 231-250, 1998.

30. W. Rothwell, Effective succession planning: Ensuring leadership continuity and building talent from within. Amacom, 2010.

\section{Published By:}


31. H. Darvish and Z. N. Temelie, "A Study on the Relationship between Succession Planning and Strategic Planning. Case Study: Payame Noor University of Aleshtar," Economic Insights-Trends \& Challenges, vol. 66, no. 1, 2014.

32. A. V. Kumar and S. Kota, "Succession Planning-A Success Story-A case study of Skyline University College," 2017.

33. B. A. M. Kamil, J. Hashim, and Z. A. Hamid, "Managing Talents in Higher Education Institutions: How Effective the Implementation of Succession Planning?," Sains Humanika, vol. 8, no. 4-2, 2016.

34. S. Stephens, "Succession planning: don't get caught off guard: planning for staff transitions," Biomedical instrumentation \& technology, vol. 50, no. 6, pp. 451-453, 2016.

35. A. K. Ishak and B. A. M. Kamil, "Succession planning at Heis: leadership style, career development and knowledge management practices as its predictors," International Review of Management and Marketing, vol. 6, no. 7S, pp. 214-220, 2016.

36. R. Bizri, "Succession in the family business: drivers and pathways," International Journal of Entrepreneurial Behavior \& Research, vol. 22, no. 1, pp. 133-154, 2016.

37. S. Salajegheh, A. Nikpour, M. Khosropour, and S. Nobarieidishe, "The Study of Related Factors with the Implementation Amount of Succession Planning System," 2014.

38. J. Ye, "Challenges of family business succession: Chinese-Australian case studies," Deakin University2013.

39. [39] Z. Jina, "Understanding the influence of culture on succession planning in South African Muslim-owned family businesses," University of Pretoria, 2014.

40. R. Sanz-Valle, J. C. Naranjo-Valencia, D. Jiménez-Jiménez, and L. Perez-Caballero, "Linking organizational learning with technical innovation and organizational culture," Journal of Knowledge Management, vol. 15, no. 6, pp. 997-1015, 2011.

41. J. L. Titzer, M. R. Shirey, and S. Hauck, "A nurse manager succession planning model with associated empirical outcomes," JONA: The Journal of Nursing Administration, vol. 44, no. 1, pp. 37-46, 2014.

42. J. Seniwoliba, "Succession planning: Preparing the next generation workforce for the University for Development Studies," 2015.

43. W. J. Rothwell, "Replacement planning: A starting point for succession planning and talent management," International Journal of Training and Development, vol. 15, no. 1, pp. 87-99, 2011.

44. C. Ringle, S. Wende, and J. Becker, "SmartPLS 3. SmartPLS GmbH, Boenningstedt," ed, 2015.

45. W. Reinartz, M. Haenlein, and J. Henseler, "An empirical comparison of the efficacy of covariance-based and variance-based SEM," International Journal of research in Marketing, vol. 26, no. 4, pp. 332-344, 2009

46. J. F. Hair, M. Sarstedt, C. M. Ringle, and J. A. Mena, "An assessment of the use of partial least squares structural equation modeling in marketing research," Journal of the academy of marketing science, vol. 40, no. 3, pp. 414-433, 2012.

47. J. L. Roldán and M. J. Sánchez-Franco, "Variance-based structural equation modeling: Guidelines for using partial least squares in information systems research," in Research methodologies, innovations and philosophies in software systems engineering and information systems: IGI Global, 2012, pp. 193-221.

48. C. Fornell and D. F. Larcker, "Evaluating structural equation models with unobservable variables and measurement error," Journal of marketing research, vol. 18, no. 1, pp. 39-50, 1981.

49. D. Barclay, C. Higgins, and R. Thompson, The partial least squares (PLS) approach to casual modeling: personal computer adoption ans use as an Illustration. 1995.

50. J. Henseler, C. M. Ringle, and M. Sarstedt, "A new criterion for assessing discriminant validity in variance-based structural equation modeling," Journal of the academy of marketing science, vol. 43, no. 1, pp. 115-135, 2015.

\section{AUTHORS PROFILE}

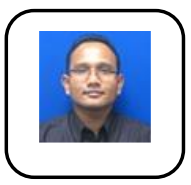

Abd Rahman Ahmad, is an associate professor at faculty of business and technology management, Universiti Tun Hussien Onn Malaysia. Abd Rahman Ahmad formal qualifications include a BHRM (UUM), MBA (Strategic Management) (IBS,UTM) and he earned PhD from Victoria University of Melbourne, Australia. He has more than 15 years working experiences as a lecturer at Universiti

Tun Hussein Onn Malaysia. The teaching experience includes strategic planning, management, entrepreneurship, and human resource management subjects. His current research interests include higher education strategic planning, education funding systems, management and more.

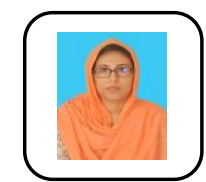

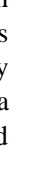

